also been documented among youth (school going and out of school). The weak government response coupled with the extremely distressing social demographics of this South-Asian republic also helps to compound the problem. The time is ripe now to prepare in advance, to take the appropriate measures to curtail further spread of the disease. If this opportunity is not utilised right now, little if at all could be done later. Islamic charities provide health, education and social services to millions of people in Pakistan. But in Pakistan still sexuality is a taboo topic. Strong hold of religious leaders on socio cultural pattern of community (attitude with extremism). Prevailing concepts to talk about sex considered as act of vulgarity and immoral activity. Word STIs and HIV/AIDS conceived as symbol of sexual delinquencies.

Method Through a Questionnaire data on knowledge, attitude, behaviour and practices related to STIs/HIV/AIDS was collected from 1200 male religious students and religious scholars from randomly selected Islamic religious centers. Baseline knowledge, attitude, acceptability of the concept were assessed.

Results According to KABP study $70 \%$ students have friends of opposite sex and due to strong religious values and restriction $30 \%$ have no friendship with opposite sex. Regarding nature of sex, $40 \%$ had kissing and only $18 \%$ had intercourse. During intercourse only $3 \%$ used condoms. $42 \%$ consider that condom is used only for family planning purpose. $56 \%$ answered that during intercourse use of condoms reduce sexual pleasure and enjoyment. 32\% youth use drugs and $38 \%$ did not know about STIs and HIV/AIDS. General discussions were also started with four Maderssas students and their teachers. These meetings addressed the sensitisation of religious scholars to the issue of HIV/AIDS and highlight the role of Maderssas in STIs and HIV prevention.

Conclusions Training of adolescent as peer educators is recommended. Ours being an Islamic society, such information should be given to youth in a way that does not challenge local norms and values. Problem-based learning and participatory education for improving knowledge and condom use and community-based interventions should be considered for STIs/HIV/AIDS prevention.

\section{P1-S2.28 SEXUALLY TRANSMITTED INFECTIONS IN SEXUALLY ABUSED CHILDREN AND ADOLESCENTS IN IBADAN, NIGERIA}

doi:10.1136/sextrans-2011-050108.85

${ }^{1} \mathrm{~S}$ A Fayemiwo, ${ }^{1} \mathrm{I}$ A Ayede, ${ }^{2} 00$ Olusanya, ${ }^{2} \mathrm{O}$ F Akinbami, ${ }^{1} \mathrm{R}$ A Bakare. ${ }^{1}$ University of Ibadan, Ibadan, Nigeria; ${ }^{2}$ University College Hospital, Ibadan, Nigeria

Background Sexual assault is a violent crime that affects men, women, and children of all ages. Sexually transmitted infections (STIs) may be transmitted during sexual assault. This study was aimed at finding the prevalence of sexually transmitted infections in potentially sexually abused children and adolescent in Ibadan.

Methods This is a descriptive cross-sectional survey of Children and adolescents referred for possible evaluation of sexual abuse at Special Treatment Clinic, University College Hospital, Ibadan between January 2006 and December 2008. Urethral, Endocervical and high vaginal swabs were collected to establish diagnosis after clinical examination and informed consent.

Results There were 18 children and adolescents with a mean age of 9.75 years ( $\mathrm{SD}=5.78$; range $2-18$ years). About $66.7 \%$ (12) had various STIs. The male to female ratio was $1: 8$. Five $(27.8 \%)$ had physical evidence of sexual assault at presentation, $4(22.2 \%)$ of which had hyperaemic labia and one had torn hymen. 12 (66.7\%) presented with vaginal discharge syndrome. The most common STI diagnosed was genital warts $(22.2 .0 \%)$. Other STIs diagnosed were vaginal candidiasis $(16.7 \%)$, bacterial vaginosis $(11.1 \%)$ and HIV (5.6\%). There was no statistical significance between HIV infection and other STIs ( $p>0.05)$.
Conclusion Our study revealed high prevalence of sexually transmitted infections among the sexually abused children and adolescents. Screening for infection should be mandatory in presumed sexually abused girls with vaginal discharge and ideally should be undertaken in all children presenting at STI clinics for evaluation of sexual abuse.

\section{P1-S2.29 RISKY SEXUAL PRACTICES AMONG YOUTH IN OUEBEC CARE CENTERS}

doi:10.1136/sextrans-2011-050108.86

${ }^{1}$ Gilles Lambert, ${ }^{2}$ Nancy Haley, ${ }^{3}$ Sandrine Jean, ${ }^{3}$ Claude Tremblay, ${ }^{2}$ JeanYves Frappier, ${ }^{4}$ Joanne Otis, ${ }^{5}$ Elise Roy. ${ }^{1}$ Institut national de santé publique du Québec, Montréal, Canada; ${ }^{2}$ Hospitalier Sainte-Justine, Université de Montréal, Canada, ${ }^{3}$ Direction de santé publique, agence de la santé et des services sociaux de Montréal, Canada; ${ }^{4}$ Université du Québec à Montréal, Canada; ${ }^{5}$ Université Sherbrooke, Canada

Background Adolescents in Youth Protection facilities are a vulnerable population, with difficult life trajectories; many of their behaviours are health compromising.

Method Youth aged 14-17, living in semi-urban and urban youth centers in Quebec were recruited on a volunteer basis to participate in the study. Socio-demographic, drug use, sexual behaviours and health service utilisation data were obtained using a structured, faceto-face interview. A urine sample was collected to test for chlamydia and gonorrhoea.

Results Between July 2008 and May 2009, 578 youth were interviewed-( $0-58 \%)$; median age- $0-16$; +15 . The majority of youth were sexually active (89\%); two thirds experienced voluntary coitarche before 14 years of age. Median number of lifetime partners was 6 ( $0-8,9-5)$. Over a third (41\%) reported group sexual activities. A large proportion of youth experienced $50 \%$ or more of their sexual activities under the influence of alcohol-18\%, cannabis-37\%, other drugs-18\%. Lifetime history of "never or rarely" using condoms was $24.7 \%$ for vaginal relations and $42.1 \%$ for anal relations ( $₫-33 \%$, $+-55 \%$ ). Protection used during last vaginal activity was-double protection (condom and another contraceptive method) $-25 \%$; condom only-32\%; contraceptive method without condom-20\%; no protection-24\%. A quarter of girls (28\%) and boys (27\%) reported an unplanned pregnancy (lifetime). Prevalence of chlamydia was-girls $9 \%$, boys $1.9 \%$. No cases of gonorrhoea were documented.

Conclusions Youth in Quebec care centers report many risky sexual behaviours, often associated with drug and alcohol use. Only a quarter of youth used protection to prevention both STIs and pregnancy during their last sexual activity. Their sejour in residential care is an opportune moment to screen these youth for risk behaviours that may compromise their future health and to provide them with personalised prevention education and health services adapted to their reality.

\section{P1-S2.30 STI AMONG VULNERABLES YOUTH ATTENDING FREE TARGETED HIV COUNSELLING AND TESTING SERVICES INCLUDING AND STI DIAGNOSIS AND MANAGEMENT IN BENIN, WEST AFRICA}

doi:10.1136/sextrans-2011-050108.87

B N Marguerite, B A Amour. Population Service International, Benin, Cotonou, Benin

Background In collaboration with two health facilities and a mobile clinic, Counselling and Testing (CT) services was implemented in two departments of Benin (Atacora and Donga) trough a project funded by the Kreditanstalt für Wiederaufbau (KfW) Germany. These interventions targeted vulnerable youth (15-24) and included 